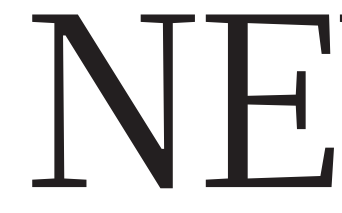

PUBLISHING Head online, there are more free papers there than was thought $\mathbf{p . 3 8 6}$
PoLIcY Romanian science in free fall with hard-won reforms unpicked p.388
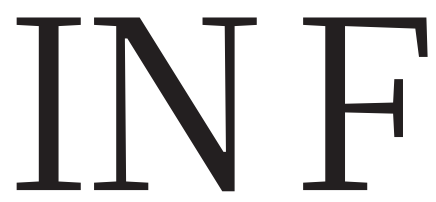

BIOTECHNOLOgY Gaps in laws could ease path for niche GM crops p.389
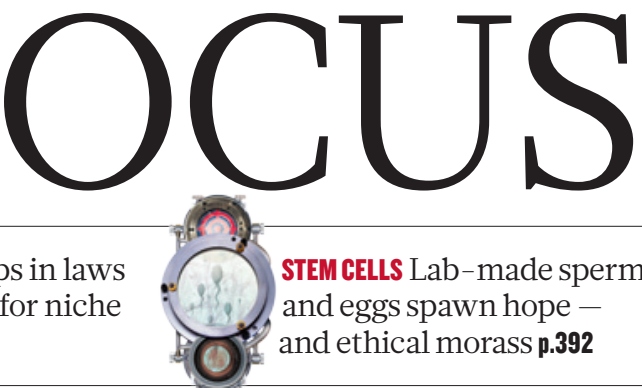

STEM CELLS Lab-made sperm and eggs spawn hope and ethical morass p.392

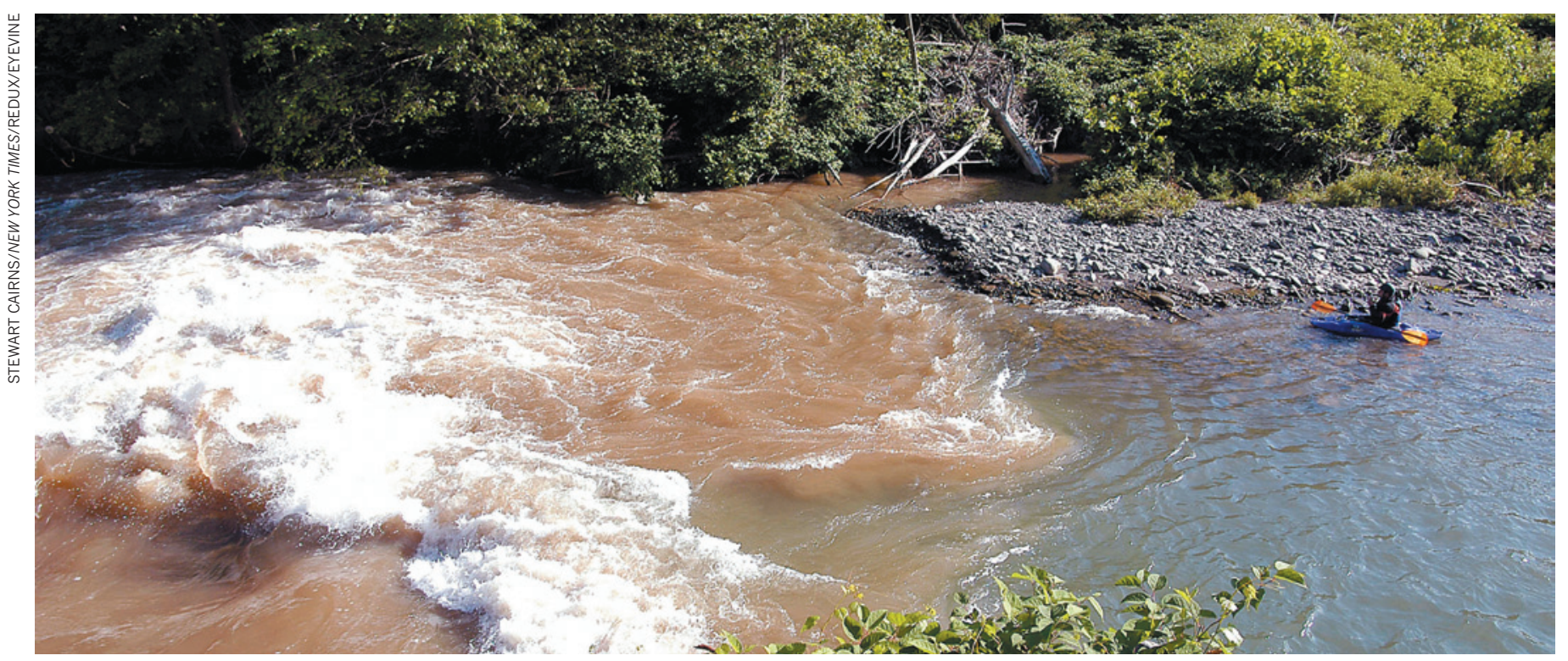

Storm runoff can introduce huge amounts of silt into the reservoir system that feeds New York's taps.

\title{
Forecasts turn tide on silt
}

\section{New York pioneers system to protect drinking water from adverse weather events.}

\section{BY JEFF TOLLEFSON}

$\mathrm{W}$ hen Hurricane Irene hammered the eastern United States in August 2011, floods sent a glut of silt into New York City's drinking-water system. The turbid waters rushed more than 100 kilometres through an aqueduct from the Catskill Mountains to the Kensico Reservoir, the last stop before the slurry would have reached millions of taps. For more than eight months afterwards, the city was forced to use an environmentally contentious chemical to rid the water of silt.

With the frequency and intensity of such siltation events on the rise, New York City is about to embark on a pioneering upgrade to its water system. The focus will not be on new dams or silt traps. Instead, starting this November, New York's reservoirs will be managed by souped-up software that automatically incorporates short-term weather forecasts and seasonal climate forecasts - helping water managers to deal with floods and droughts.

Hydrologists far beyond the Big Apple will be watching closely. New York's programme depends on a streamflow-forecasting system developed by the US National Weather Service, which aims to implement the system nationwide in the coming years. "This project opens the door to a more quantitative use of seasonal climate forecasts, which will help people make better decisions," says Andrew Wood, a hydrologist at the National Center for Atmospheric Research in Boulder, Colorado. Australia is now experimenting with a similar forecasting system, and the European Commission Joint Research Centre has also rolled out a floodprediction system.

But New York will be one of the first cities to connect the forecasts to a water-management system. Its immediate goal is to manage storm runoff to meet water-quality standards

\section{DNATURE.COM}

Read more in

Nature's special on

water resources:

go.nature.com/vrtrdc without adding costly new infrastructure to the system, a network of 19 reservoirs and 3 lakes that collectively hold more than 2 trillion litres of water. Under normal circumstances, managers handle siltation by holding water in reservoirs and letting silt settle out. But several times since 2005, the city has had to let silty water flow all the way to Kensico, where it was then treated with aluminium sulphate - a chemical that causes silt particles to coagulate and sink. State and federal regulators have raised concerns about buildup of aluminium sulphate in reservoir sediments, and its potential effects on fish and aquatic organisms.

The new system is designed to help the city to cope with major siltation episodes, which are expected to increase as the climate warms. With better warning of impending storms, water managers can drain certain reservoirs ahead of time and alleviate the potential for siltation. The software also takes seasonal forecasts into account, allowing managers to work out 
various conservation strategies if, for example, drier weather is expected.

"For years, we've done this by ourselves, just trying to balance all of this in our heads," says Jim Porter, who heads water operations for the city's department of environmental protection. "Hopefully, we can predict out a little further into the future."

The potential savings are enormous. Coping with the silt problem by building a new intake system at one reservoir or increasing the size of a second reservoir would cost between US\$200 million and $\$ 500$ million. A new filtration plant could run to more than $\$ 10$ billion. By contrast, the city's analysis suggests that an integrated reservoir-management system can tackle the problem for roughly $\$ 8$ million.

But to make it happen, the city first needs better streamflow forecasts. Although the National Weather Service makes streamflow predictions, it has until now done so mainly by comparing current conditions - precipitation, soil moisture, snowpack and streamflow - with historical averages, and then extrapolating the results. This approach assumes that streamflows will evolve as they have in the past under similar circumstances, but does not look ahead to future conditions.

The incoming system - years in the making - combines short-term and seasonal precipitation forecasts, and adds those predictions into the streamflow forecasts. To validate the system, the National Weather Service checked its predictions against historical data.

New York is paying the Weather Service about \$1 million to accelerate the process so that the system will be available for use this year. "We now have something that is ready for prime time," says John Schaake, a hydrologist and independent consultant in Baltimore, Maryland, who helped to develop the streamflow-forecast system.

The system will be available at 5 of the 12 regional US river-forecast centres, although it is unclear when it will become standard nationally. There are budget constraints, and each centre will have to customize the system. "There's a lot of interest, but the question is how you institutionalize that," says Kevin Werner, a hydrologist at the Colorado Basin River Forecast Center in Salt Lake City, Utah.

And it is also unclear whether others will follow New York's lead and hitch the forecasts to a reservoir-management system. Demonstrating that the forecasts improve water management should help to ease doubts, says Daniel Sheer, president of HydroLogics Incorporated in Columbia, Maryland, which is providing New York with the reservoir-management software. "There will be much broader interest in the forecasts if we can show that they work." -
PUBLISHING

\section{Half of 2011 papers now free to read}

\section{Boost for advocates of open-access research articles.}

\section{BY RICHARD VAN NOORDEN}

$O^{\mathrm{e}}$ earch the Internet for any research article published in 2011, and you have a 50-50 chance of downloading it for free. This claim - made in a report ${ }^{1}$ produced for the European Commission - suggests that many more research papers are openly available online than was previously thought. The finding, released on 21 August, is heartening news for advocates of open access. But some experts are raising their eyebrows at the high numbers.

There has been a steady move over the past few years towards getting research papers that are funded by government money into the public domain, and the best estimates ${ }^{2,3}$ for the proportion of papers free online run at around

\section{FREEDOM ONLINE}

At least" $43 \%$ of research papers published during 2008-11 are now free online, but the proportion varies by country and discipline.

$$
\text { - Published in open-access journal }
$$
- Total free online ${ }^{\dagger}$

Discipline

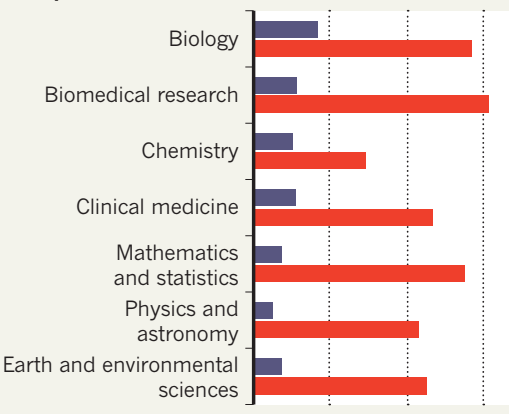

Country

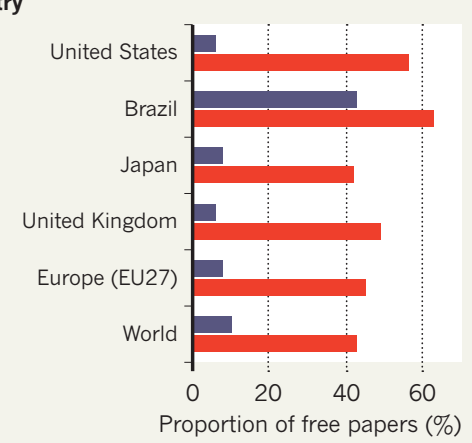

The true proportion is likely to approach $50 \%$, because automated software does not find every free paper. made free by subscription journals, as well as self-archived free papers.
$30 \%$. But these are underestimates, argues Éric Archambault, the founder and president of Science-Metrix, a consultancy in Montreal, Canada, that conducted the analysis for the European Commission.

The firm initially asked a team led by Stevan Harnad, an open-access campaigner and cognitive scientist at the University of Quebec in Montreal, to check a random sample of 20,000 papers published in 2008 (from the Scopus database of papers run by Elsevier). It used a program designed by Yassine Gargouri, a computer scientist at the same university, to find free articles. The team found that $32 \%$ of the papers that it downloaded in December 2012 were freely available. But when Archambault's group checked 500 of these papers manually using Google and other search engines and repositories, the figure rose to $48 \%$.

On the basis of this initial test, ScienceMetrix applied its own automated software, or 'harvester', to 320,000 papers downloaded from 2004 to 2011; the tool searches publishers' websites, institutional archives, repositories such as arXiv and PubMed Central, and sites such as the academic networking site ResearchGate and the search engine CiteSeer ${ }^{\mathrm{X}}$.

It found that an average of $43 \%$ of articles published during 2008-11 are available online for free, with the results varying by country and discipline (see 'Freedom online'). But the true figure is probably higher, because the harvester does not pick up every free paper. When the incompleteness is adjusted for, the proportion of free articles from 2011 rises to about $50 \%$, says Archambault.

The report "confirms my optimism", says Peter Suber, director of the Office for Scholarly Communication at Harvard University in Cambridge, Massachusetts, and a proponent of open access to research. He thinks that it reflects the experiences of working scientists today. "When researchers hit a paywall online, they turn to Google to search for free copies - and, increasingly, they are finding them," he says.

The rise of open-access journals is part of the explanation: the share of papers published in these journals rose from $4 \%$ in 2004 to $12 \%$ by 2011 , the report found — agreeing with figures published last year by Bo-Christer Björk, who

\section{$\rightarrow$ NATURE.COM}

For more on open-access publishing, visit: go.nature.com/gdtvaw 